\title{
Intususcepción colónica causada por lipoma de colon
}

\author{
Colonic intussusception caused by colonic lipoma
}

David Daroch M. ${ }^{1,2}$ y Daniella Espínola M. ${ }^{1,2}$

Mujer de 41 años sin antecedentes mórbidos, consulta por cuadro de 2 semanas de dolor abdominal cólico que cede parcialmente con antiespasmódicos, al examen físico destaca masa palpable en flanco derecho.

Estudio con tomografía axial computarizada (TC) evidencia imagen sugerente de lipoma colónico que determina invaginación de segmento del colon transverso (Figuras 1 y 2).

Se realiza colonoscopia que muestra lipoma impactado de colon transverso, se logra desimpactación endoscópica (Figura 3). Al día 2 poscolonoscopia se realizó colectomía parcial derecha con anastomosis mecánica terminolateral laparoscópica. Biopsia: lipoma submucoso de 5 x 4 x 4 centímetros (Figura 4).

El lipoma de colon es el segundo tumor benigno más frecuente de colon, siendo el primero los adenomas $^{1,2}$. Alcanza una prevalencia en las autopsias entre $0,2-4,4 \%{ }^{2,3}$. Es un tumor submucoso $(90 \%)$, de crecimiento lento, únicos (75-95\%), la mayoría son asintomáticos y se encuentran más frecuentemente en el colón ascedente y ciego $(75 \%)^{3-5}$.

El diagnóstico se realiza principalmente mediante enema baritado, colonoscopia y/o $\mathrm{TC}^{3}$.

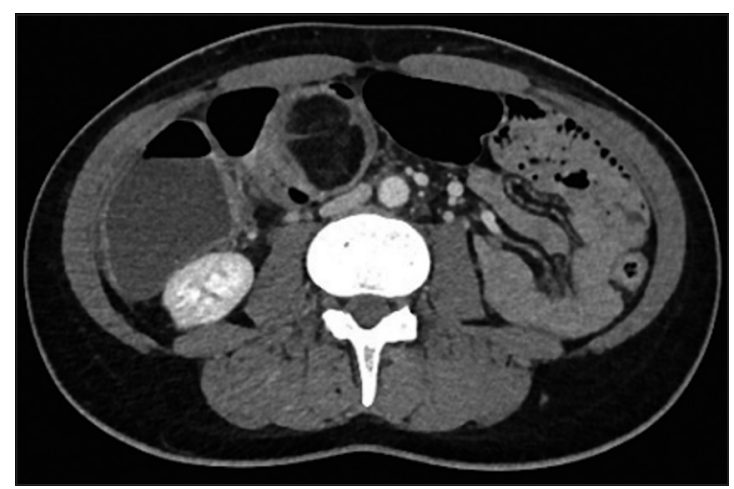

Figura 1. TC. Corte transversal. Lipoma colónico que determina invaginación de segmento del colon transverso.

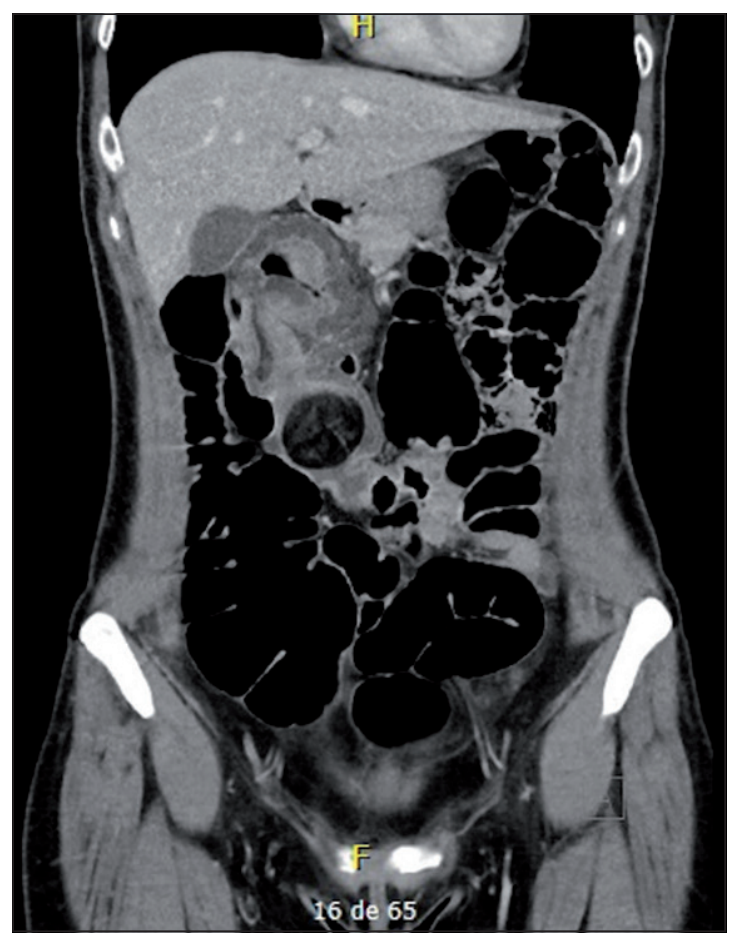

'Clínica Alemana de Santiago. ${ }^{2}$ Hospital Padre Hurtado. Universidad del Desarrollo. Santiago, Chile.

Recibido el 16 de mayo de 2017, aceptado para publicación el 11 de julio de 2017.

\section{Correspondencia a:}

David Daroch M. dadaroch@gmail.com
Figura 2. TC. Corte coronal. Lipoma colónico que determina invaginación de segmento del colon transverso.

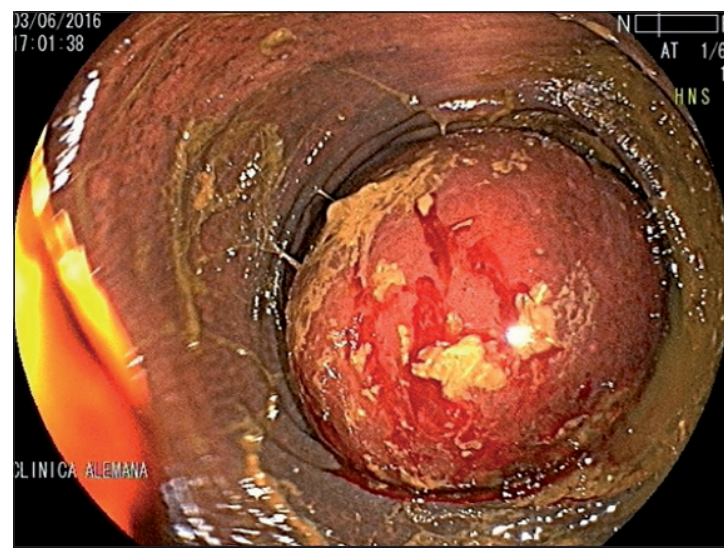

Figura 3. Colonoscopia. Lipoma de colon transverso impactado en lumen. 


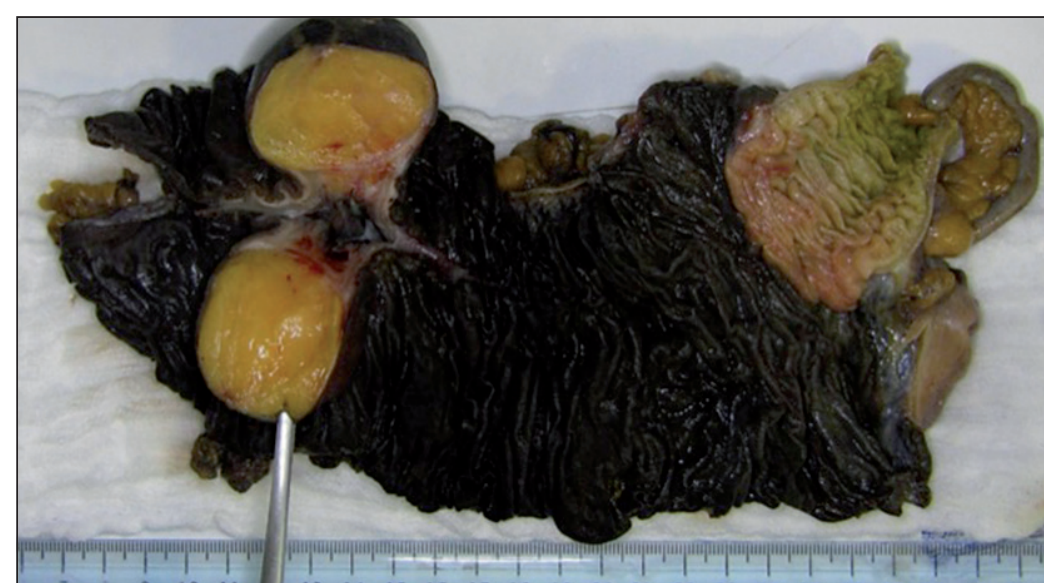

Figura 4. Pieza quirúrgica enviada a anatomía patológica. Pinza indica lipoma, en negro la mucosa colónica normal.

Lipomas sintomáticos o $>3 \mathrm{~cm}$. tienen indicación de resección por persistencia de síntomas y riesgo de complicación, respectivamente. Frecuentemente la resección es quirúrgica por el riesgo de perforación, sobre todo: lipomas $>2 \mathrm{~cm}$, lesiones sésiles y lesiones que comprometen capas musculares o serosa ${ }^{3}$

\section{Responsabilidades éticas}

Protección de personas y animales. Los autores declaran que para esta investigación no se han realizado experimentos en seres humanos ni en animales.

Confidencialidad de los datos. Los autores declaran que han seguido los protocolos de su centro de trabajo sobre la publicación de datos de pacientes.

Derecho a la privacidad y consentimiento informado. Los autores declaran que en este artículo no aparecen datos de pacientes.

\section{Conflicto de intereses}

Los autores declaran no tener ningún conflicto de intereses.

\section{Bibliografía}

1. Thonet G, Setton J, García M, Russi M. Lipomas de colon, a propósito de 2 casos. Rev Chil Cir. 2003;55:274-6.

2. Megaly M, Yacoub G. Transverse Colon Submucosal Lipoma Presenting With Colocolic Intussusception. ACG Case Rep
J. 2016;3:158-9.

3. Lee JM, Kim JH, Kim M, Kim JH, Lee YB, Lee JH, et al. Endoscopic submucosal dissection of a large colonic lipoma: Report of two cases. World J Gastroenterol. 2015;21: 3127-31.

4. Dassanayake SU, Dinamithra NP,
Nawarathne NM. Submucosal lipoma of the sigmoid colon as a rare cause of mucoid diarrhea: a case report. J Med Case Rep. 2016;10:17.

5. Butte JM, Iñiguez A, Torres J, Ortega C, Martínez J, Zúñiga A, et al. Intususcepción de colon por lipoma. Reporte de 2 casos. Rev Chil Cir. 2006;58:151-4. 